\title{
PENERAPAN COGNITIF BEHAVIOR THERAPI (CBT) PADA IBU NIFAS SEBAGAI UPAYA PENCEGAHAN DEPRESI POST PARTUM DI KABUPATEN KLATEN
}

\author{
Murwati, Suroso \\ Kementerian Kesehatan Politeknik Kesehatan Surakarta Jurusan Kebidanan
}

\begin{abstract}
Cognitive Behavior Teraphi, Postpartum Depression. Postpartum mothers who are unable to adjust to their new role may experience psychological disorders such as postpartum depression. In Klaten found $36.7 \%$ postpartum experienced postpartum depression (Imaninditya, Murwati, 2014). Family support and good health care proved to have an effect on the postpartum depression (Wahyuni, et al, 2014). In addition, cognitive intervention is needed that can overcome the condition of the post-partum mother. This research design is quasi experiment type post test control group design, sample is normal postpartum mother day to 10 - 40, BPM working area of health office of Klaten regency, the sample size is 25 treatment group and 25 control group with Purposive consequtive sampling technique. The act of using CBT(Cognitive Behavior therapy)-based Cognitive Counseling Guidelines and for measuring DPP using EPDS (Edinburg postnatal Depression Scale). The study found 16\% depression syndrome in the treatment group and 52\% in the control group. The value of $p=0.014$, the application of CBT in the postpartum mother can prevent the occurrence of postpartum depression.
\end{abstract}

Keywords: Cognitive Behavior Teraphi, Postpartum Depression

Abstrak: Cognitif Behavior Teraphi, Depresi Postpartum. Ibu Postpartum yang tidak berhasil menyesuaikan diri dengan peran barunya dapat mengalami gangguan psikologis seperti depresi postpartum (DPP). Di Klaten ditemukan 36,7\% ibu nifas mengalami DPP (Imaninditya, Murwati, 2014). Dukungan keluarga dan tenaga kesehatan yang baik terbukti berpengaruh terhadap DPP (Wahyuni, dkk, 2014). Selain itu diperlukan intervensi kognitif yang dapat mengatasi kondisi pada ibu post partum tersebut. Desain penelitian ini adalah quasi eksperiment jenis post test control group design, sampel adalah Ibu postpartum normal hari ke 10 - 40, di BPM Wilayah kerja Dinas Kesehatan Kabupaten Klaten, besar sampel sebanyak 25 orang kelompok perlakuan dan 25 orang kelompok kontrol dengan tehnik Purposive consequtive sampling. Tindakan menggunakan Panduan Konseling Ibu Nifas berbasis CBT( Cognitive Behavior terapi) dan untuk mengukur DPP menggunakan EPDS (Edinburg postnatal Depression Scale). Hasil penelitian ditemukan syndrome depresi sebanyak $16 \%$ pada kelompok perlakuan dan 52\% pada kelompok kontrol. Nilai $p=0,014$, penerapan $C B T$ pada Ibu postpartum dapat mencegah terjadinya depresi postpartum.

Kata Kunci: Cognitif Behavior Teraphi, Depresi Postpartum 
Post partum adalah masa yang dimulai sesudah kelahiran bayi dan berakhir setelah lebih kurang 6 minggu. Pada masa ini terjadi perubahan fisik dan psikologis. Secara umum ada tiga gangguan psikologis utama pasca persalinan, dari yang ringan sampai berat, yaitu postpartum blues, depresi post partum dan post partum psikosis. Ibu postpartum yang tidak dapat beradaptasi dengan peran barunya dapat terjadi depresi postpartum. Depresi postpartum (DPP) adalah suatu depresi yang ditemukan pada perempuan setelah melahirkan, yang terjadi dalam kurun waktu 4 (empat) minggu, beberapa bulan bahkan beberapa tahun bila tidak diatasi dengan baik. Pendapat lain menyebutkan DPP dapat terjadi mulai 6 minggu sampai 1 tahun (Corwin,E,J,Ph.D \& Pajer,K, 2008).

Prevalensi DPP didunia sebesar 13\% (Lori E. et al.2009), untuk wilayah Asia Afrika berkisar 25\% - 60\% (Corey \& Tapha, 2011). Rerata angka kejadian DPP di Indonesia adalah $11-30 \%$ (Elvira S. D. 2006).

Gejala yang sering muncul pada DPP adalah sedih, menangis, cepat tersinggung, cemas, sulit untuk berkonsentrasi, labilitas perasaan serta gangguan tidur dan nafsu makan, lebih berat lagi ditemukan ada pikiran bunuh diri, waham paranoid dan melakukan ancaman kekerasan terhadap bayinya (Corwin,E,J,Ph.D \& Pajer,K, 2008).

Faktor penyebab DPP cenderung kompleks dan masih belum jelas. Perubahan hormonal pasca persalinan ditengarai berhubungan dengan symptom depresif dan sedikit faktor biologis yang dapat menjelaskan terjadinya depresi pasca persalinan (Corey \& Tapha, 2011) .
Faktor yang mempengaruhi terjadinya Depresi Post Partum, ada riwayat depresi, kegelisahan selama kehamilan, konflik perkawinan, adanya tekanan hidup atau pengalaman hidup tidak menyenangkan, dukungan sosial yang rendah, status ekonomi yang rendah dan adanya komplikasi obstetrik (Stewart, et al. 2003)

Depresi postpartum bisa berdampak negatif pada kesehatan ibu, anak dan keluarga. Pada ibu dapat menurunkan kemampuan dalam mengasuh anak, ketertarikan terhadap bayinya kurang, tidak berrespon positif terhadap bayinya dan malas menyusui. Sehingga akan mempengaruhi kesehatan, pertumbuhan dan perkembangan sang bayi.(Fitelson.et al,2011)

Upaya penanganan Depresi Postpartum meliputi pengobatan medis, terapi psikologi, psikososial dan penanganan tanpa obat seperti latihan, akupunktur dan massage terapi (Fitelson.et al,2011).

Program nasional kunjungan ulang masa nifas dilakukan minimal 3 kali meliputi deteksi dini, pencegahan dan menangani komplikasi ( Muchtar,A. Sursilah, I. Isir, M. Dkk., 2014). Kunjungan ini dinilai belum menyentuh aspek psikologis, padahal ibu nifas mengalami perubahan tidak hanya fisik namun juga psikologis dan sosial. Demikian juga dukungan keluarga dan tenaga kesehatan yang baik terbukti berpengaruh terhadap depresi postpartum (Wahyuni, Murwati, \& Supiati, 2014). Model kunjungan rumah oleh profesional dengan intervensi pencegahan DPP yang terstruktur berhasil meningkatkan kesehatan ibu dan anak (Barnes, Senior, \& MacPherson, 2009) Hasil penelitian lain menyatakan bahwa terapi kognitif dapat 
menurunkan depresi pasca salin (Haerani dan Moordiningsih, 2009).

Untuk itu diperlukan suatu bentuk intervensi kognitif yang dapat mengatasi perubahan suasana hati dan perasaan tidak mampu pada ibu post partum yang gagal beradaptasi sehingga tidak berlanjut menjadi DPP dan malas menyusui (Diaz, V. A., \& Carolyn, C. 2012)

\section{METODE PENELITIAN}

Desain penelitian ini adalah quasi eksperiment. Adapun jenisnya adalah post test control design (Kothari, 2004). Pengambilan data penelitian dilakukan pada bulan Juli - Agustus tahun 2016 di BPM Wilayah kerja Dinas Kesehatan Kabupaten Klaten. Sampel adalah sebagian Ibu postpartum normal hari ke 10 - 40, sebanyak 25 orang kelompok intervensi dan 25 orang kelompok control (Dahlan,M,2010). Tehnik pengambilan sampel : Purposive consequtive sampling. Analisis Data dengan Analisa Univariat dan Analisa Bivariat dengan Uji statistika Unpaired t-test dan dilanjutkan uji regresi liner sederhana dengan persamaan $\mathrm{Y}=\mathrm{a}+$ bx (Dahlan,M,2014b). Penelitian ini telah mendapatkan persetujuan untuk dilaksanakan (ethical clearance) dari Komite Etik Penelitian Kesehatan Fakultas Kedokteran Universitas Negeri Sebelas Maret Surakarta dan mendapatkan izin untuk melakukan pengambilan data dari Kepala Badan Perencanaan Pembangunan Daerah (BAPPEDA) Kabupaten Klaten.

\section{HASIL PENELITIAN}

Tabel 1

Distribusi frekuensi ibu postpartum yang dilakukan Asuhan Nifas dan CBT di BPM Wilayah Kerja Dinas Kesehatan Kabupaten Klaten

\begin{tabular}{|c|c|c|c|c|c|}
\hline \multirow[t]{2}{*}{ No } & \multirow[t]{2}{*}{ Variabel } & \multicolumn{2}{|c|}{$\begin{array}{l}\text { Kelompok } \\
\text { Intervensi }\end{array}$} & \multicolumn{2}{|c|}{$\begin{array}{c}\text { Kelompok } \\
\text { Kontrol }\end{array}$} \\
\hline & & n & $\%$ & $\mathbf{n}$ & $\%$ \\
\hline \multirow[t]{4}{*}{1} & Umur ibu & & & & \\
\hline & 1. $<20^{\text {th }}$ atau $>35^{\text {th }}$ & 6 & 24 & 5 & 20 \\
\hline & 2. $20-35^{\text {th }}$ & 19 & 76 & 20 & 80 \\
\hline & TOTAL & 25 & 100 & 25 & 100 \\
\hline \multirow[t]{4}{*}{2} & Paritas & & & & \\
\hline & 1. Primipara & 9 & 36 & 5 & 20 \\
\hline & 2. Multipara & 16 & 64 & 20 & 80 \\
\hline & TOTAL & 25 & 100 & 25 & 100 \\
\hline \multirow[t]{4}{*}{3.} & Pekerjaan Ibu & & & & \\
\hline & 1. Tidak bekerja & 14 & 56 & 14 & 56 \\
\hline & 2. Bekerja & 11 & 44 & 11 & 44 \\
\hline & TOTAL & 25 & 100 & 25 & 100 \\
\hline \multirow[t]{6}{*}{4} & Pendidikan ibu & & & & \\
\hline & SD & 0 & 0 & 1 & 4 \\
\hline & 2. SMP & 9 & 36 & 6 & 24 \\
\hline & 3. SMA & 10 & 40 & 14 & 56 \\
\hline & 4. $\mathrm{PT}$ & 6 & 24 & 4 & 16 \\
\hline & TOTAL & 25 & 100 & 25 & 100 \\
\hline \multirow[t]{4}{*}{5} & Riwayat Abortus & & & & \\
\hline & 1. Ada & 2 & 8 & 4 & 16 \\
\hline & 2. Tidak ada & 23 & 92 & 21 & 84 \\
\hline & TOTAL & 25 & 100 & 25 & 100 \\
\hline \multirow[t]{4}{*}{6} & Riwayat persalinan & & & & \\
\hline & 1. Tindakan & 1 & 4 & 7 & 28 \\
\hline & 2. Spontan & 24 & 96 & 18 & 72 \\
\hline & TOTAL & 25 & 100 & 25 & 100 \\
\hline \multirow[t]{7}{*}{7} & $\begin{array}{l}\text { Tingkat Depresi } \\
\text { Kelompok } \\
\text { Intervensi } \\
\end{array}$ & & & & \\
\hline & a. $\quad$ Normal & 21 & 84 & 12 & 48 \\
\hline & b. Ringan & 4 & 16 & 9 & 36 \\
\hline & c. $\quad$ Sedang & & & 1 & 4 \\
\hline & $\begin{array}{ll}\text { d. } & \text { Berat }\end{array}$ & & & 3 & 12 \\
\hline & TOTAL & 25 & 100 & 25 & 100 \\
\hline & Perbandingan & or & $\mathrm{PPP}$ & $\mathrm{pa}$ & \\
\hline \multicolumn{6}{|c|}{$\begin{array}{l}\text { kelompok intervensi sesudah dilakukan } \\
\text { asuhan nifas dan konseling CBT hanya } \\
\text { terdapat } 4 \text { orang dengan depresi ringan, } \\
\text { hal ini lebih sedikit jumlahnya }\end{array}$} \\
\hline
\end{tabular}


dengan asuhan nifas ditemukan 13 orang dengan depresi dari ringan sampai berat.

\section{Tabel 2}

Hasil uji Bivariat Unpaired t-test Pengaruh Penerapan CBT Terhadap Depresi Postpartum di BPM Wilayah Kerja Dinas Kesehatan Kabupaten

\begin{tabular}{|c|c|c|c|c|c|}
\hline \multicolumn{6}{|c|}{ Klaten } \\
\hline NO & $\begin{array}{l}\text { Skor } \\
\text { DPP }\end{array}$ & $\mathbf{n}$ & $\begin{array}{c}\text { Rerat } \\
\text { a }\end{array}$ & $\begin{array}{c}\text { Perbedaan } \\
\text { mean }\end{array}$ & $P$ \\
\hline 1 & $\begin{array}{c}\text { Kelompo } \\
\text { k KF + } \\
\text { CBT }\end{array}$ & 25 & 6.56 & 2.6 & $\begin{array}{c}0.01 \\
4\end{array}$ \\
\hline 2 & $\begin{array}{c}\text { Kelompo } \\
\text { k KF }\end{array}$ & 25 & 9.16 & & \\
\hline
\end{tabular}

Hasil uji unpaired t-test diperoleh nilai significancy 0.014 , hal ini berarti “ ada perbedaan mean skor DPP yang bermakna antara kelompok intervensi dan kelompok kontrol ". Dengan demikian dapat disimpulkan bahwa ada pengaruh penerapan CBT terhadap depresi postpartum.

\section{Tabel 3}

\section{Hasil Uji regresi linier sederhana} Pengaruh penerapan CBT terhadap Depresi Postpartum di BPM Wilayah kerja DKK Klaten

\begin{tabular}{lll}
\hline Adjusted $\mathrm{R}^{2}$ & Nilai $p$ & $\begin{array}{l}\text { Persamaan } \\
\text { regresi }\end{array}$ \\
\hline $13,3 \%$ & 0,41 & $4,516+0,223 \mathrm{KF}$ \\
\hline
\end{tabular}

Hasil Uji regresi linier di dapatkan persamaan linieritasnya adalah penerapan CBT $=4,516+0,223 \mathrm{KF}$. Hal ini berarti bahwa penerapan CBT pada ibu nifas dapat menurunkan skor depresi sebesar 4,516 dibandingkan dengan asuhan nifas tanpa pemberian konseling berbasis CBT.

\section{PEMBAHASAN}

Pada penelitian ini, ibu nifas sesudah diberi perlakuan asuhan nifas dan konseling berbasis CBT ditemukan sebagian besar dalam keadaan normal atau tidak depresi meskipun ada sedikit yang mengalami depresi ringan, sementara itu ibu nifas ada yang mengalami depresi ringan, sedang dan bahkan ada yang berat pada asuhan nifas tanpa konseling berbasis CBT.

Hasil analisis bivariat menunjukkan bahwa ada pengaruh penerapan CBT terhadap depresi postpartum yang ditunjukkan dengan nilai $p<0.014$. Berdasar uji regresi bahwa penerapan CBT dapat mengurangi 4,5 skor pada pengukuran DPP berdasar skala EPDS, meskipun hal ini hanya dapat menjelaskan sekitar 13,3\%, sementara $86,7 \%$ nya kemungkinan disebabkan oleh kondisi lain yang tidak diteliti.

Berdasar metodologis, hasil penelitian ini kemungkinan dipengaruhi berbagai keterbatasan yang tidak dapat dihindari, seperti bias seleksi, informasi dan pengontrolan terhadap perancu. Pengaruh bias ini dapat memperbesar atau memperkecil pengaruh paparan sesungguhnya.

Jaminan kausalitas dalam penelitian ini berdasarkan kriteria konsistensi yang dikembangkan berdasarkan kajian literature baik texbook maupun penelitian sebelumnya tentang faktor - faktor yang mempengaruhi depresi postpartum termasuk teori dan konsep CBT pada ibu post partum.

Hasil penelitian ini sesuai dengan beberapa penelitian bahwa pemberian psikoedukasi termasuk konseling berbasis CBT adalah salah satu upaya pencegahan DPP. Upaya penanganan Depresi Postpartum meliputi pengobatan, terapi psikologi, psikososial dan penanganan tanpa obat seperti latihan, akupunktur dan massage terapi (Fitelson.et al,2011).

CBT terbukti secara ilmiah untuk pengobatan pasien dengan depresi, dan dalam pelaksanaanya harus 
memahami sifat dan penerapan CBT; akses sumber daya profesional yang mendukung kolaborasi efektif dengan pasien dan konsultan. CBT dikembangkan oleh Aaron Beck, yang beralasan bahwa beberapa orang belajar memandang diri, dunia, dan masa depan dipengaruhi oleh berbagai bias. Kesalahan kognitif membuat seseorang dapat mengembangkan keyakinan disfungsional yang menyebabkan perilaku tidak efektif (coping), perasaan depresi dan gejala fisik yang tidak menyenangkan.

CBT berfokus pada hubungan antara pikiran, sikap, perilaku, reaksi fisik dan lingkungan; memberikan pendidikan tentang keterkaitan antara masing-masing domain; dan termasuk strategi yang menargetkan perubahan positif di setiap domain. CBT telah diterapkan untuk mengobati berbagai gangguan kejiawaan termasuk depresi, kecemasan dan gangguan makan, dengan tingkat keberhasilan yang dilaporkan antara 52\% menjadi 97\% (Misri,S \& Kendrick, K, 2007).

\section{KESIMPULAN DAN SARAN}

Hasil uji unpaired t-test diperoleh nilai significancy 0.014 , hal ini berarti “ ada perbedaan mean skor DPP yang bermakna antara kelompok intervensi dan kelompok kontrol ". Dengan demikian dapat disimpulkan bahwa ada pengaruh penerapan CBT terhadap depresi postpartum. Hasil Uji regresi linier di dapatkan persamaan linieritasnya adalah penerapan $\mathrm{CBT}=4,516+0,223 \mathrm{KF}$. Hal ini berarti bahwa penerapan CBT pada ibu nifas dapat menurunkan skor depresi sebesar 4,516 dibandingkan dengan asuhan nifas tanpa pemberian konseling berbasis CBT.
Memberikan pelayanan asuhan nifas dengan konseling berbasis CBT sebagai upaya pencegahan terjadinya DPP dan sebagai salah satu terapi nonfarmakologis dan psikoedukasi selain terapi konvensional.

\section{DAFTAR RUJUKAN}

Barnes, J., Senior, R., \& MacPherson, K. (2009). The utility of volunteer home-visiting support to prevent maternal depression in the first year of life. Child: Care, Health and Development, 35(6), 807-16. http://doi.org/10.1111/j.13652214.2009.01007.x

Corey.E and Thapa.S, (2011) Postpartum Depression: An Overview of Treatment and Prevention : World Health Organization Department of Reproductive Health and Research,Geneva, 2011.

Corwin,E,J,Ph.D \& Pajer,K.(2008) The Psychoneuroimmunologyof postpartum depresion. Journal of women Health, http://do.org/10.1089/jwh.2007.07 $\underline{25}$

Dahlan.M. (2010). Besar Sampel dan cara Pengambilan Sampel (dalam penelitian Kedokteran dan Kesehatan). Jakarta : Salemba Medika

Dahlan, M. . (2014b). Statistik Untuk Kedokteran dan Kesehatan. Deskriptif, Bivariat dan Multivariat dilengkapi dengan menggunakan SPSS (6th ed.). Jakarta: Epidemiologi Indonesia.

Diaz, V. A., \& Carolyn, C. (2012). Integrating Cognitive Behavioral Therapy into the Management of Depression. American Family Physician, 85(7). 
Elvira S. D. (2006). Depresi Pasca Persalinan. Jakarta: FK UI

Fitelson E, Kim S, Baker A and Leight K. Treatment of Postpartum Depression:Clinical, Psychological and Pharmacological Options. International Journal of Women's Health 2011; 1(3): 1-14.

Haerani dan Moordiningsih. (2009). Terapi Kognitif dan Depresi Pasca Melahirkan. Jurnal Intervensi Psikologi, 1(1), 117 - 124.

Imaninditya, Y., Murwati. (2014). Studi Deskriptif Tingkat Depresi Postpartum pada Ibu Nifas di Wilayah Kerja Puskesmas Klaten Selatan. Jurnal Kebidanan Indonesia, 5(1), 27-34.

Kothari, 2004. Research Methodology (Methods and Tehniques) second ed. New Delhi: New Age International.

Lori E. Ross and Cindy-Lee Dennis (2009) The Prevalence of Postpartum depression among Women with Substance Use, an Abuse History, or Chronic Illness: A Systematic Review Journal Of Women's Health Volume 18, Number 4, 2009

Muchtar,A. Sursilah, I. Isir, M. Dkk. (2014). Kesehatan Ibu dan Anak Continumm of Carelife Cycle. Jakarta. Pusdiklatnakes.

Misri,S. \& Kendrick, K. (2007). Treatment of perinatal mood and anxiety disorder : a review. Canadian Journal of Psychiatry, 52(8)

Stewart, D.E., Robertson, E., Dennis, CL., Grace, S.L., \& Wallington, T. (2003). Postpartum depression: Literature Review of Risk Factors and Interventions. Toronto.
Wahyuni, S., Murwati, \& Supiati. (2014). Faktor Internal Dan Eksternal Yang mempengaruhi Depresi Postpartum. Jurnal Terpadu Ilmu Kesehatan, 3(2), 106-214. 